\title{
A Phase II study of trabectedin single agent in patients with recurrent ovarian cancer previously treated with platinum-based regimens
}

\section{CN Krasner*,', DS McMeekin², S Chan ${ }^{3}$, PS Braly ${ }^{4}$, FG Renshaw ${ }^{5}$, S Kaye ${ }^{6}$, DM Provencher ${ }^{7}$, S Campos ${ }^{8}$ and ME Gore ${ }^{6}$ for the ET-743-INT-II study group ${ }^{9}$}

'Department of Medical Oncology, Massachusetts General Hospital, Boston, MA, USA; ${ }^{2}$ Department of Gynecologic Oncology, University of Oklahoma Health Science Center, Oklahoma City, OK, USA; ${ }^{3}$ Department of Clinical Oncology, Nottingham City Hospital, Nottingham, UK; ${ }^{4}$ Department of Gynecologic Oncology, Hematology and Oncology Specialists, New Orleans, LA, USA; ${ }^{5}$ Oncology Therapeutics, Johnson \& Johnson Pharmaceutical Research \& Development, L.L.C., Raritan, NJ, USA; ${ }^{6}$ Department of Medicine, Royal Marsden Hospital, London, UK; ${ }^{7}$ Department of Gynecologic Oncology, CHUM, Hôpital Notre-Dame, Montreal, Canada; ${ }^{8}$ Department of Medical Oncology, Dana Farber Cancer Institute, Boston, MA, USA

The objective of this study was to determine the objective response rate in patients with platinum-sensitive and platinum-resistant recurrent ovarian cancer to treatment with trabectedin (Yondelis ${ }^{\mathbb{B}}$ ) administered as a 3-h infusion weekly for 3 weeks of a 4-week cycle. We carried out a multicentre Phase II trial of trabectedin in patients with advanced recurrent ovarian cancer. Trabectedin $\left(0.58 \mathrm{mg} \mathrm{m}^{-2}\right)$ was administered via a central line, after premedication with dexamethasone, to I 47 patients as a 3-h infusion weekly for 3 weeks followed by I-week rest. Major eligibility criteria included measurable relapsed advanced ovarian cancer and not more than two prior platinum-containing regimens. Patients were stratified according to the treatment-free interval (TFI) between having either platinum-sensitive ( $\geqslant 6$ months TFI) or platinum-resistant disease ( $<6$ months TFI)/platinum-refractory disease (progression during first line therapy). In the platinum-sensitive cohort, 62 evaluable patients with measurable disease had an overall response rate (ORR) of 29.0\% (95\% Cl: 18.2-41.9\%) and median progression-free survival (PFS) was 5.I months (95\% Cl: 2.8-6.2). Four patients with measurable disease per Response Evaluation Criteria in Solid Tumours (RECIST) criteria had no follow-up scans at the end of treatment. In the platinum-resistant/refractory cohort, 79 patients were evaluable with an ORR of 6.3\% (95\% Cl: 2.I - I4.2\%). Median PFS was 2.0 months (95\% Cl: 1.7-3.5 months). Two patients with measurable disease per RECIST criteria had no follow-up scans at the end of treatment. The most frequent ( $\geqslant 2 \%$ of patients) drug-related treatment-emergent grade $3 / 4$ adverse events were reversible liver alanine transferase elevation (10\%), neutropaenia (8\%), nausea, vomiting, and fatigue (5\% each). Trabectedin is an active treatment, with documented responses in patients with platinum sensitive advanced relapsed ovarian cancer, and has a manageable toxicity profile.

British Journal of Cancer (2007) 97, 1618-1624. doi:10.1038/sj.bjc.6604088 www.bjcancer.com

Published online 13 November 2007

(C) 2007 Cancer Research UK

Keywords: trabectedin; ovarian cancer; overall response rate; platinum-sensitive; platinum-resistant; progression-free survival

Ovarian cancer is often diagnosed in advanced stages due to the absence of overt signs or symptoms in earlier-stage disease, with poor long-term prognosis and 5-year survival rates $<30 \%$ (American Cancer Society, 2005). Standard therapy is cytoreductive

*Correspondence: Dr CN Krasner, Massachusetts General Hospital, 100 Blossom St Cox 5, Boston, MA 02114, USA;

E-mail: cnkrasner@partners.org

9 ET-743-INT-I I Study Group. Canada: M. Fung Kee Fung, P. Ghatage, D. Provencher, M. Roy; France: H Curé, A Hardy-Bessard, C Lhommé, E Pujade-Lauraine, I Ray-Coquard; The Netherlands: R de Jong, B Slangen; UK: S Chan, J Graham, M Gore, P Harper, S Kaye, S Pledge, S Vasanthan; USA: P Braly, S DelPrete, D Doering, A Garcia, A Gordon, C Krasner, $S$ McMeekin

Received 19 March 2007; revised II October 2007; accepted 17 October 2007; published online 13 November 2007 surgery followed by platinum-based chemotherapy. Despite high initial response rates, relapse and chemo-resistance eventually occur in the majority of patients with advanced disease (Markman and Bookman, 2000; Harper, 2002).

The National Institute of Health and Clinical Excellence (NICE) of United Kingdom guidelines (Technology Appraisal Guidance, 2005) recommend that patients with recurrent ovarian cancer should be classified by their duration of the response to initial platinum therapy: those with disease recurrence $\geqslant 12$ months after initial therapy are regarded as platinum-sensitive, whereas those with recurrence 6 to $>12$ months after initial therapy are regarded as partial platinum-sensitive (Gordon et al, 2001). Women who recur $\leqslant 6$ months after initial therapy are considered platinumresistant and are less likely to receive further benefit from platinum. Women with disease progression during initial platinum therapy are regarded as platinum-refractory and require no further platinum therapy. 
Few effective single agents are available for second-line and subsequent therapy following progression on platinum and taxanes (Markman and Bookman, 2000; Gordon et al, 2001). Current single agent chemotherapy options for patients include: re-treatment with a platinum-based regimen or single agent pegylated liposomal doxorubicin, topotecan, or gemcitabine, which have shown response rates in the range of $16-40 \%$ (Gordon et al, 2001; Markman et al, 2001; Garcia et al, 2004; Papadimitriou et al, 2004; National Comprehensive Cancer Network, 2005; Rose, 2005).

Trabectedin (ET-743, Yondelis ${ }^{\circledR}$, PharmaMar, SA, Madrid, Spain and Johnson \& Johnson Pharmaceutical Research \& Development, LLC, Raritan, NJ, USA) is a tris, tetrahydroisoquinoline alkaloid isolated originally from the marine ascidian Ecteinascidia turbinate and currently produced synthetically. It binds to the minor groove of DNA at the N2 position of guanine, inducing a bend towards the major groove (Pommier et al, 1996; Zewail-Foote and Hurley, 1999; van Kesteren et al, 2003). Trabectedin inhibits transcription of heat shock-inducible genes (Minuzzo et al, 2000) and interacts with the transcription-coupled nucleotide excision repair (TC-NER) system, resulting in formation of lethal DNA strands, cell cycle arrest, and apoptosis by a process that is p53 independent (Erba et al, 2001; Takebayashi et al, 2001). In vitro, low concentrations $(2-80 \mathrm{nM})$ of trabectedin disrupt progression of human cancer cells through $\mathrm{S}$ phase, resulting in accumulation in late $\mathrm{S}$ and $\mathrm{G}_{2} / \mathrm{M}$ (Martinez et al, 2001; Mandola et al, 2005). Recent data also suggest that the enzyme poly ADP-ribose polymerase (PARP) may contribute to the cellular sensitivity of trabectedin (Mandola et al, 2005).

Trabectedin has shown in vitro cytotoxicity against melanoma, ovarian, colorectal, breast, brain, and lung cancer cell lines (Jimeno et al, 1996). Soft-tissue sarcoma cell lines have proven to be highly sensitive to growth inhibition in picomolar concentrations (Li et al, 2001). Similarly, growth in human solid tumour colony-forming assays was inhibited (Izbicka et al, 1998). Trabectedin also inhibits the development of human tumour xenografts in mice, including melanoma, ovarian cancer, nonsmall cell lung cancer, breast, and renal cell carcinomas, with cures in some models (Jimeno et al, 1996; Valoti et al, 1998; Hendriks et al, 1999). Valoti et al, (1998) found trabectedin active against xenografts, inducing long-lasting tumour regressions both in early and established tumours. Of note, activity was observed in ovarian xenograft tumours that are sensitive to Cisplatin as well as those which are resistant to cisplatin.

In Phase I studies, trabectedin showed activity in patients with ovarian cancer (Salazar et al, 2006), mesothelioma (Ryan et al, 2001), leiomyosarcoma (Villalona-Calero et al, 2002), melanoma (Ryan et al, 2001), breast cancer (Taamma et al, 2001), endometrial carcinoma (McMeekin et al, 2004), liposarcoma (Taamma et al, 2001), osteosarcoma (Taamma et al, 2001), and soft-tissue sarcomas (Yovine et al, 2004). Doses evaluated included 1- to 72-h infusions administered every 3 weeks, 1 -h infusion daily for 5 days every 3 weeks, and a 3-h infusion once weekly for 3 out of 4 weeks (Ryan et al, 2001; Villalona-Calero et al, 2002; Twelves et al, 2003). The once weekly regimen for 3 out of 4 weeks appeared to provide antitumour activity with the benefit of improved patient tolerability and convenience of administration. Therefore, the current protocol was initiated at the time of the onset of initial Phase II studies.

A Phase II study conducted by the Southern Europe New Drugs Organization Foundation (SENDO) evaluated the use of trabectedin in 59 patients with advanced disease including refractory or relapsing ovarian cancer following a platinum-taxane regimen (Sessa et al, 2005). An initial dose of $1.65 \mathrm{mg} \mathrm{m}^{-2}$ (reduced to $1.3 \mathrm{mg} \mathrm{m}^{-2}$ ) was administered as a 3 -h infusion every 3 weeks. An overall response rate (ORR) of $43.5 \%$, one complete response (CR) and nine partial responses (PR), was reported in 23 evaluable platinum-sensitive patients. The duration of the patient who achieved a CR was 8.7 months. The patients who achieved PR had a median time to progression (TTP) of 7.9 months, and an additional nine patients exhibited stable disease (SD). The 28 patients with evaluable platinum resistance yielded an ORR of $7.1 \%, 2$ patients with PR each with a TTP of 4 and 4.6 months. Stable disease was reported in eight $(28.6 \%)$ additional patients. The $1.3 \mathrm{mg} \mathrm{m}^{-2}$ dose was well tolerated with transient increase in aminotransferases and non-fatal (G3) neutropaenia.

The present Phase II trial evaluated trabectedin as a single agent administered weekly for 3 of 4 weeks in patients with advanced relapsed ovarian cancer previously treated with a platinum-based regimen. This study was initiated when the appropriate schedule and dosing of trabectedin had not been determined. The primary objective was to determine the ORR in patients with platinumsensitive and -resistant disease. Secondary objectives included duration of response, TTP, progression-free survival (PFS), overall survival (OS), and safety.

\section{MATERIALS AND METHODS}

\section{Patient population}

Eligibility criteria included histologically proven epithelial ovarian carcinoma, fallopian tube carcinoma, or primary peritoneal carcinoma (excluding peritoneal mesothelioma) treated with one to two prior platinum-containing regimens (if the second was started following a progression-free interval of $\geqslant 6$ months after the first regimen); age $\geqslant 18$ years; Eastern Cooperative Oncology Group (ECOG) performance status of 0 or 1; at least 1 measurable lesion according to Response Evaluation Criteria in Solid Tumours (RECIST) (Therasse et al, 2000) guidelines; adequate haematologic (haemoglobin $>9.0$ g per $100 \mathrm{ml}$, absolute neutrophil count (ANC) $>1500$ per $\mu \mathrm{l}$, platelets $\geqslant 100000$ per $\mu \mathrm{l}$ ), renal (serum creatinine $\leqslant$ ULN), and hepatic function (total bilirubin $\leqslant$ ULN, total alkaline phosphatase $\leqslant$ ULN (or if $>$ ULN, alkaline phosphatase liver fraction or $5^{\prime}$-nucleotidase $\left.\leqslant \mathrm{ULN}\right)$, AST and ALT $\leqslant 2.5 \times$ ULN, and albumin $\geqslant 2.5 \mathrm{gl}^{-1}$ ). The patient population in this study included platinum-sensitive, -resistant, and -refractory patients receiving second or third line therapy.

Exclusion criteria included prior trabectedin exposure; one prior non-platinum-containing regimen in platinum-sensitive patients (more specific exclusion added after a protocol amendment); more than two prior chemotherapy regimens; $<4$ weeks from radiation therapy hormonal therapy, biological therapy, any investigational agent; peripheral neuropathy $\geqslant$ grade 2 ; history of other neoplastic disease (unless remission for $>5$ years); known CNS metastasis or other serious illness; and pregnant or lactating women or those of childbearing potential not employing adequate contraception.

The Independent Ethics Committee/Independent Review Board of each participating site approved the study. All patients gave written informed consent.

\section{Study design and evaluations}

This multicentre, open-label, single-arm Phase II trial enrolled patients in two prospectively defined cohorts: a platinum-sensitive cohort, defined as relapse after a disease-free interval $\geqslant 6$ months from the end of the last platinum-based chemotherapy; or a platinum-resistant cohort, defined as disease progression $<6$ months from the end of the last platinum-based treatment. A 2stage design was used to minimise exposure to dose and schedule of trabectedin until tolerability and efficacy were established.

Vital signs, haematologic parameters, blood chemistry, liver panels, and physical examinations were performed at baseline (within 14 days before administration of first drug dose) and throughout the study including treatment termination. Disease evaluations were made per RECIST guidelines (Therasse et al, 
2000) utilising either CT or MRI. CA 125 levels were measured at screening, after every two cycles, and at study termination. Patients without measurable disease, clinical progression, or study discontinuations without radiology documentation at the end of the study were considered non-evaluable for response.

\section{Dosage and administration}

Trabectedin was diluted in $500 \mathrm{ml}$ of saline and administered via a central venous catheter. This resulted in two patients with tissue extravasations due to catheter-related malfunctions. A dose of $0.58 \mathrm{mg} \mathrm{m}^{-2}$ was administered once weekly as a 3 -h infusion for 3 weeks, on a 28-day cycle. All patients were premedicated with $10 \mathrm{mg}$ dexamethasone IV $30 \mathrm{~min}$ before trabectedin infusion, since dexamethasone pretreatment has been shown in animal and clinical studies to ameliorate the hepatotoxic effects of trabectedin by diminishing hepatocellular exposure to the drug (Puchalski et al, 2002; Sarah et al, 2003). Treatment was continued as long as clinical benefit was derived or until disease progression. Trabectedin was discontinued after patients received at least two cycles beyond a confirmed CR (McMeekin et al, 2005).

\section{Dose reductions and discontinuations}

A maximum of two dose reductions (from 0.58. to 0.49 then to $0.40 \mathrm{mg} \mathrm{m}^{-2}$ ) were permitted based on toxicity. Prophylactic use of haematopoietic colony-stimulating factors was not permitted in the first cycle. In subsequent cycles, they could be used for secondary prophylaxis according to institutional and American Society of Clinical Oncology guidelines (American Society of Clinical Oncology). Treatment delays up to 3 weeks were permitted for persistent toxicity; beyond this, therapy was discontinued. Patients were withdrawn because of serious adverse events, disease progression, or consent withdrawal.

\section{Response and toxicity assessment}

Tumour assessment was performed at baseline, every other treatment cycle until disease progression, and at the end of treatment. After completion of the treatment phase, patients were followed for survival every 3 months until death or a predetermined cutoff date approximately 2 months from last patient treatment termination. Adverse events were assessed at each treatment visit, treatment termination, and during follow-up. Toxicities were graded according to the National Cancer Institute Common Toxicity Criteria V2.0 (National Cancer Institute).

\section{Statistical methods}

Sample size for each group was determined using a Simon 2-stage design. For the platinum-sensitive group, 23 patients were enrolled in the first stage. If at least four responders were observed, approximately 25 additional patients were enrolled until 48 platinum-sensitive patients were evaluable for response per RECIST guidelines. This design had $80 \%$ power to reject a response rate of $15 \%$ at a $5 \%$ significance level when the true response rate was $30 \%$. In the platinum-resistant group, 30 patients were enrolled in the first stage. If at least two responders were observed, approximately 22 additional patients were enrolled until 52 platinum-resistant patients were evaluable for response per RECIST guidelines. This design had $80 \%$ power to reject a response rate of $5 \%$ at a $5 \%$ significance level when the true response rate was $15 \%$.

For efficacy results, patients were further classified into subgroups based on TTP from initial platinum therapy: platinum-sensitive recurrence $\geqslant 12$ months after initial platinum-based therapy; partial-platinum-sensitive recurrence 6 to $<12$ months after initial therapy; platinum-resistant recurrence $\leqslant 6$ months after initial therapy; platinum-refractory, progression during initial platinum therapy. For final intent-to-treat efficacy analysis, response rate, TTP, PFS, OS, the 28 patients whose platinum sensitivity status on enrolment was unknown on initial review, but later resolved, were appropriately added back to either the platinum-sensitive or -resistant/refractory patient populations.

Prognostic factors including baseline ECOG performance status scores; number of platinum-based lines of therapy before enrolment; TTP from the start of last dose of chemotherapy, histology; histology grade; or CA125 levels at baseline were analysed for correlation with ORR.

Summaries of safety were based on laboratory data and treatment-emergent adverse events (TEAE), defined as any adverse event occurring on or after the first dose of trabectedin and within 30 days after the last dose.

\section{RESULTS}

\section{Patient characteristics}

Between October 2002 and September 2004, a total of 170 patients were screened for enrolment. Baseline characteristics for treated patients were similar for the platinum-sensitive and -resistant cohorts, with the exception of ECOG performance status (Table 1). Of the screened patients, 147 were part of the intent-to-treat population (23 patients were screen failures) and 141 were evaluable for efficacy per RECIST guidelines at the end of study treatment (Table 2). Nearly, all patients received prior cytoreductive surgery $(98 \%)$, and $5 \%$ had previous radiotherapy. All patients had received prior platinum-containing chemotherapy. In the platinum-sensitive patient cohort, $74 \%$ had 1 prior line and $26 \%$ had 2 prior lines. Median time from the last chemotherapy regimen to the first dose was 11 months. In the platinum-resistant/ refractory patient cohort, $65 \%$ had 1 prior line and $35 \%$ had 2 prior lines, median time from the last chemotherapy regimen to the first dose was 4.1 months.

\section{Treatment}

The 66 platinum-sensitive patients received 304 cycles with a median of four cycles per patient (range, 1-11); median treatment duration was 18.6. weeks (range, 4.0-77); median cumulative dose was $6.5 \mathrm{mg} \mathrm{m}^{-2}$ (range, 1-15); and median dose intensity was $0.353 \mathrm{mg} \mathrm{m}^{-2}$ per week (range, $0.17-0.44$ ) with a relative dose intensity of $81.1 \%$ (range, $38-102 \%$ ). For the 81 platinumresistant/refractory patients, 284 total cycles were administered with a median of two cycles (range, 1.0-22.0); treatment duration was 8.9 weeks (range, 4.0-98.0), median cumulative dose was $3.5 \mathrm{mg} \mathrm{m}^{-2}$ (range, 1.0-37.0), median dose intensity was $0.391 \mathrm{mg} \mathrm{m}^{-2}$ per week (range, $0.14-0.46$ ), and the relative dose intensity was $90.0 \%$ (range, $32-105 \%$ ).

For the platinum-sensitive patients, $42 \%$ had at least one cycle delay, $45 \%$ had at least one dose withheld, and $42 \%$ had at least one dose reduction. In the platinum-resistant/refractory patient cohort, $28 \%$ had at least one cycle delay, $20 \%$ had at least one dose withheld, and $23 \%$ had at least one dose reduction. Reasons for dose delays and reductions in both cohorts were divided equally between liver transaminase elevations and myelosuppression. Twenty-one of $66(31.8 \%)$ patients in the platinum-sensitive cohort and 8 of $79(10.1 \%)$ in the platinum-resistant cohort remained on therapy $>6$ months.

\section{Efficacy}

Efficacy and survival data are shown in Table 3. Both statistical response targets (for platinum-sensitive and -resistant patients) were reached in our study. The 62 evaluable patients in the platinum-sensitive cohort had an ORR of $29.0 \%$ (27.3\% of the total 
Table I Demographics and baseline characteristics in treated patients

\begin{tabular}{|c|c|c|c|}
\hline & $\begin{array}{c}\text { Platinum } \\
\text { sensitive } \\
(N=66)\end{array}$ & $\begin{array}{c}\text { Platinum } \\
\text { resistant } \\
(N=8 I)\end{array}$ & $\begin{array}{c}\text { Total } \\
(N=147)\end{array}$ \\
\hline \multicolumn{4}{|l|}{ Race, $n$ (\%) } \\
\hline$N$ & 66 & 81 & 147 \\
\hline Black & $4(6)$ & $2(2)$ & $6(4)$ \\
\hline White & $61(92)$ & $76(94)$ & $137(93)$ \\
\hline Asian & 0 & $\mathrm{I}(\mathrm{I})$ & I (I) \\
\hline Other & I (2) & $2(2)$ & $3(2)$ \\
\hline \multicolumn{4}{|l|}{ Age } \\
\hline N & 66 & 81 & 147 \\
\hline Category, n (\%) & & & \\
\hline $18-<40$ & $3(5)$ & $2(2)$ & $5(3)$ \\
\hline $40-<60$ & $29(44)$ & $4 \mid(51)$ & $70(48)$ \\
\hline$\geqslant 60$ & $34(52)$ & $38(47)$ & $72(49)$ \\
\hline Mean (s.d.) & $60.1(10.43)$ & $58.3(9.98)$ & $59.1(10.19)$ \\
\hline Median & 60.0 & 59.0 & 59.0 \\
\hline Range & $(36 ; 83)$ & $(33 ; 83)$ & $(33 ; 83)$ \\
\hline \multicolumn{4}{|l|}{ Baseline weight in kilograms } \\
\hline N & 66 & 81 & 147 \\
\hline Mean (s.d.) & $71.58(18.213)$ & $69.15(13.869)$ & $\begin{array}{c}70.24 \\
(15.955)\end{array}$ \\
\hline Median & 68.45 & 69.00 & 68.60 \\
\hline Range & $(36.0 ; 167.0)$ & $(42.3 ; 121.8)$ & $(36.0 ; 167.0)$ \\
\hline \multicolumn{4}{|l|}{ Baseline ECOG Score, $n$ (\%) } \\
\hline N & 66 & 81 & 147 \\
\hline 0 & $46(70)$ & $47(58)$ & $93(63)$ \\
\hline I & $20(30)$ & $34(42)$ & $54(37)$ \\
\hline \multicolumn{4}{|l|}{ Histology, n (\%) } \\
\hline$N$ & 66 & 80 & 146 \\
\hline Endometrioid & $8(12)$ & $3(4)$ & II (8) \\
\hline Clear cell carcinoma & $2(3)$ & $5(6)$ & $7(5)$ \\
\hline Mixed epithelial tumour & I (2) & $2(3)$ & $3(2)$ \\
\hline Papillary/serous & $49(74)$ & $59(74)$ & $108(74)$ \\
\hline $\begin{array}{l}\text { Transitional carcinoma } \\
\text { (Brenner) }\end{array}$ & I (2) & 0 & I (I) \\
\hline Peritoneal carcinoma & I (2) & $2(3)$ & $3(2)$ \\
\hline Fallopian tube carcinoma & I (2) & $2(3)$ & $3(2)$ \\
\hline Other & $3(5)$ & $7(9)$ & $10(7)$ \\
\hline \multicolumn{4}{|l|}{ Histology grade, n (\%) } \\
\hline$N$ & 66 & 79 & 145 \\
\hline $\begin{array}{l}\text { Grade I (well- } \\
\text { differentiated) }\end{array}$ & I (2) & $3(4)$ & $4(3)$ \\
\hline $\begin{array}{l}\text { Grade } 2 \text { (moderately } \\
\text { differentiated }\end{array}$ & $16(24)$ & $12(15)$ & $28(19)$ \\
\hline $\begin{array}{l}\text { Grade } 3 \text { (poorly } \\
\text { differentiated) }\end{array}$ & $44(67)$ & $56(7 \mid)$ & $100(69)$ \\
\hline Unknown & $5(8)$ & $8(10)$ & $13(9)$ \\
\hline \multicolumn{4}{|l|}{$\begin{array}{l}\text { Previous lines systemic } \\
\text { therapy, } n(\%)\end{array}$} \\
\hline$N$ & 66 & 81 & 147 \\
\hline I Prior platinum line & $49(74)$ & $53(65)$ & $102(69)$ \\
\hline 2 Prior platinum line & $17(26)$ & $28(35)$ & $45(3 \mathrm{I})$ \\
\hline
\end{tabular}

platinum-sensitive population) (4CR, 14PR) (95\% CI: $18.2-$ $41.9 \%)$. Partial platinum-sensitive patients $(n=39)$ yielded an ORR of $25.6 \%$ (1CR, 9PR); SD in $13(33.3 \%)$; disease control $(\mathrm{CR}+\mathrm{PR}+\mathrm{SD})$ in $23(60.0 \%)$; and disease progression in $16(40 \%)$ patients. The platinum-sensitive subgroup $(n=23)$ had an ORR of $34.8 \%$ (3CR, 5PR); SD in 9 (39.1\%).

The 79 evaluable patients in the platinum-resistant/refractory patient cohort had an ORR of $6.3 \%$ (6.2\% of the total platinumresistant/refractory population) (5PR) (95\% CI: $2.1-14.2 \%)$. The platinum-resistant subgroup $(n=42)$ had an ORR of $4.8 \%$ (2PR),
Table 2 Patient profile

\begin{tabular}{|c|c|c|c|}
\hline $\begin{array}{l}\text { Reason for Withdrawal/ } \\
\text { Termination }\end{array}$ & $\begin{array}{c}\text { Platinum } \\
\text { sensitive } \\
(\mathbf{N}=66) \\
n(\%)\end{array}$ & $\begin{array}{c}\text { Platinum } \\
\text { resistant } \\
(\mathbf{N}=8 \mathrm{I}) \\
n(\%)\end{array}$ & $\begin{array}{c}\begin{array}{c}\text { Total } \\
(N=147)\end{array} \\
n(\%)\end{array}$ \\
\hline Total no. of subjects enrolled & $66(100)$ & $81(100)$ & $147(100)$ \\
\hline $\begin{array}{l}\text { Treated } \\
\text { Evaluable for efficacy per RECIST } \\
\text { Guidelines }\end{array}$ & $62(94)$ & $79(98)$ & $|4|(96)$ \\
\hline $\begin{array}{l}\text { Ongoing } \\
\text { Complete response (confirmed) } \\
\text { Adverse event/drug-related } \\
\text { Adverse event/not drug -related } \\
\text { Disease progression } \\
\text { Subject ineligible to continue } \\
\text { Subject choice } \\
\text { Other }\end{array}$ & $\begin{array}{c}3(5) \\
3(5) \\
6(9) \\
2(3) \\
42(64) \\
0 \\
2(3) \\
4(6)\end{array}$ & $\begin{array}{c}3(4) \\
0 \\
2(2) \\
6(7) \\
57(70) \\
1(1) \\
3(4) \\
7(9)\end{array}$ & $\begin{aligned} 6 & (4) \\
3 & (2) \\
8 & (5) \\
8 & (5) \\
99 & (67) \\
1 & (1) \\
5 & (3) \\
11 & (7)\end{aligned}$ \\
\hline $\begin{array}{l}\text { Not evaluable for efficacy per RECIST } \\
\text { Guidelines } \\
\text { Death } \\
\text { Adverse event/drug-related } \\
\text { Adverse event/not drug -related } \\
\text { Subject choice }\end{array}$ & $\begin{array}{l}\text { I }(2) \\
0 \\
1(2) \\
2(3)\end{array}$ & $\begin{array}{c}0 \\
I(1) \\
0 \\
I(1)\end{array}$ & $\begin{array}{l}6(4) \\
1(1) \\
1(1) \\
1(1) \\
3(2)\end{array}$ \\
\hline
\end{tabular}

Note: percentages calculated with the number of subjects in each group as denominator.

SD in $21(50.0 \%)$, and disease progression in $19(45.2 \%)$ patients. The platinum-refractory subgroup $(n=37)$, ORR was $8.1 \%(3 \mathrm{PR})$, SD in 15 (40.5\%), and disease progression in 19 (51.3\%) patients. Six patients of the total patient population were not evaluable because of early death, clinical progression, or early discontinuation unrelated to toxicity.

\section{Secondary efficacy end points}

Secondary efficacy end points included time to response, duration of response, PFS, and OS. In the platinum-sensitive cohort, the partial platinum-sensitive subgroup had a median time to response of 1.8 months (range, 2-5); median duration of response, 5.2 months (95\% CI: 3.7-5.8); and a median PFS of 4.0 months $(95 \%$ CI: $1.7-6.1$ ). In the platinum-sensitive subgroup ( $>12$ month treatment-free interval), the median time to response was 1.9 months (range, 2-5); median duration of response was not estimable (NE) because very few patients had disease progression; and median PFS was 5.1 months (95\% CI: 3.1-6.5) (Table 3).

The platinum-resistant subgroup (including platinum-resistant/ refractory patient cohort) had a median time to response of 2.5 months (range, 2-3); median duration of response, 4.2 months; and a median PFS of 2.3 months (95\% CI: 1.7-4.1). The platinumrefractory subgroup had median time to response of 5.6 months (range, 2-12); median duration of response, 11.0 months; and a median PFS of 1.9 months (95\% CI: 1.6-2.6) (Table 3).

In the overall platinum-sensitive cohort, TTP was 5.2 months (95\% CI: 3.1 -6.5 months) and PFS was 5.1 months (95\% CI: $2.8-$ 6.2 months). Overall survival was NE because very few patients have died, with a 1-year survival rate of $55.9 \%$. The overall platinum-resistant cohort had a TTP of 2.0 months (95\% CI: 1.77 3.5 months), PFS of 2.0 months (95\% CI: $1.7-3.5$ months), and OS of 10.7 months with a 1 -year survival rate of $24.5 \%$ (Table 3 ).

No statistically significant correlation was noted between the prognostic factors analysed and ORR, PFS, and OS, which may be explained, in part, by the small sample size.

The concurrence rate between CA125 response (defined as either a decrease of at least $50 \%$ in value or normalisation, confirmed 
Table 3 Efficacy results

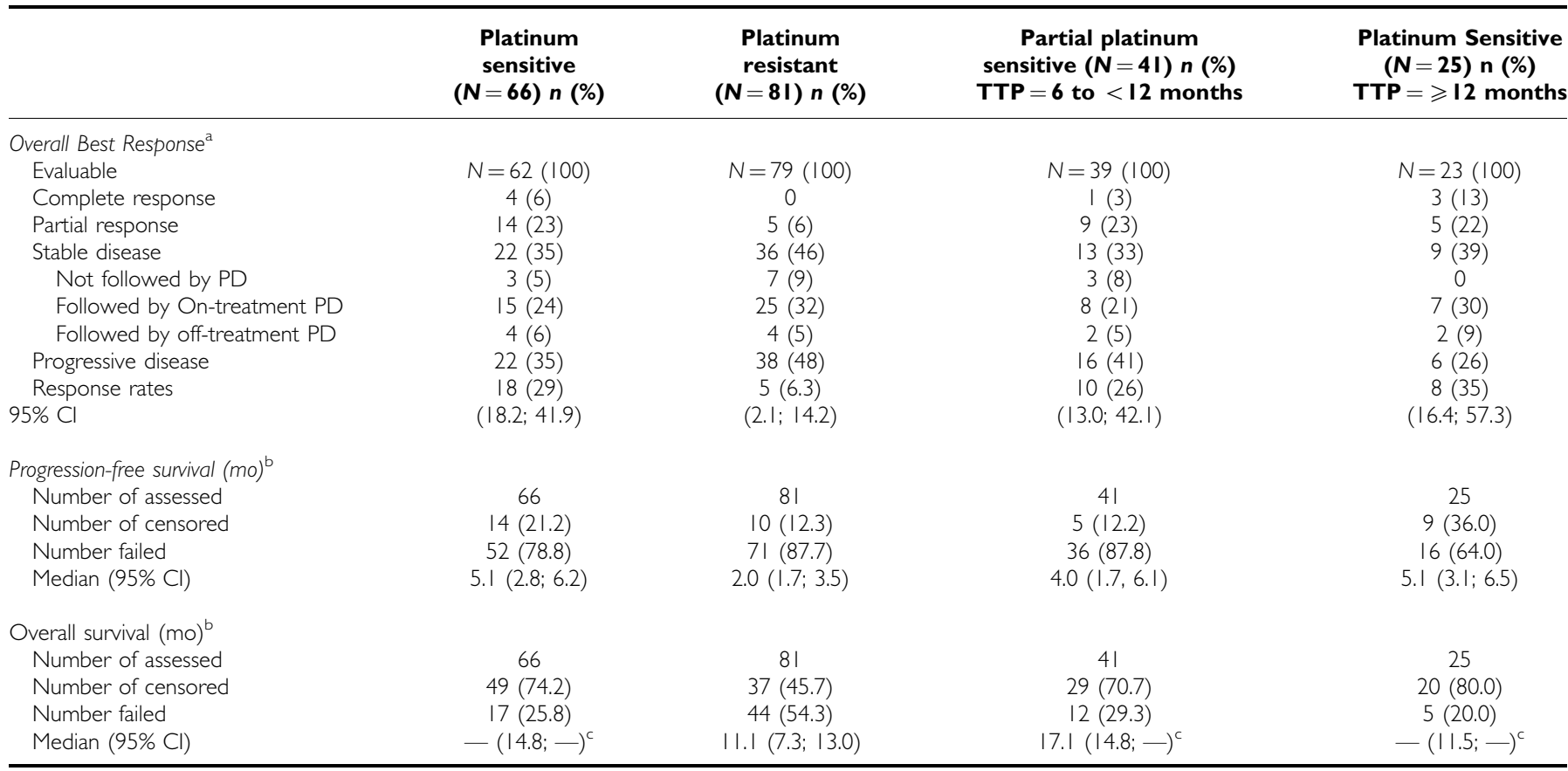

Note: partial platinum-sensitive: TTP $=6$ to $<12$ months from end of last platinum-based treatment; Platinum-sensitive: TTP $\geqslant 12$ months from end of last platinum-based treatment. ${ }^{a}$ All evaluable patients. ${ }^{b}$ Based on Kaplan-Meier product limit estimates. ${ }^{c}(-)$ Some medians, and lower and upper limits of confidence intervals not estimable.

after at least 28 days) and objective response was $80 \%$ in platinumsensitive patients and $90 \%$ in platinum-resistant patients. The concurrence rate between CA125 response and objective response, including SD ( $>4$ month) patients, was decreased to $77 \%$ in platinum-sensitive patients and $69 \%$ in platinum-resistant patients.

\section{Toxicity}

Of the 147 patients treated, $146(99 \%)$ reported at least one laboratory abnormality (worst CTC grade) while on treatment. A drug-related grade $3 / 4$ TEAE was reported for $39 \%$ of the treated subjects, and in $14 \%$ of cycles of therapy. The most common worst grade 3/4 laboratory abnormalities reported were elevated ALT $(12 \% / 0 \%)$, hyponatraemia $(8 \% / 1 \%)$, neutropaenia $(7 \% / 1 \%)$, and hypoalbuminaemia $(7 \% / 0 \%)$ (Table 4$)$.

The most common TEAEs causing dose modifications were elevated ALT (20\%), granulocytopaenia (18\%), increased alkaline phosphatase $(16 \%)$, and infusion site complications (7\%). Drugrelated TEAEs that led to discontinuation of treatment were reported for $11(7 \%)$ patients.

All 147 treated patients were included for safety analysis. Most commonly reported drug-related grade 3/4 TEAEs occurring in $\geqslant 2 \%$ of evaluable patients were elevated ALT (11\%), granulocytopaenia (6\%), and nausea, vomiting, and fatigue (5\% each). Incidence of alopecia was $9 \%$ with no drug-related grade $3 / 4$ events. The most frequently drug-related TEAEs (grades $1-4)$ were nausea $(67 \%)$, vomiting $(56 \%)$, fatigue $(60 \%)$, constipation $(33 \%)$, abdominal pain $(11 \%)$, and anorexia ( $28 \%$ each) (Table 5$)$.

Five subjects died during study treatment or within 30 days of the last dose of the study drug. Disease progression was reported as the cause of death for two subjects, and death was attributed to drug-related TEAEs for one subject due to drug-related grade 3 dyspnoea, pulmonary oedema, central chest pain, heart murmur, bilateral pleural effusion, pulmonary hypertension, and left cardiac failure reported as the cause of death at Cycle 7. Non-drug-related
Table 4 Worst on-treatment ${ }^{\mathrm{a}}$ grade I-4 laboratory abnormalities

\begin{tabular}{|c|c|c|c|c|}
\hline Lab type ${ }^{b}$ & $\begin{array}{c}\text { Grade I } \\
\text { n (\%) }\end{array}$ & $\begin{array}{c}\text { Grade } 2 \\
n \text { (\%) }\end{array}$ & $\begin{array}{c}\text { Grade } 3 \\
n(\%)\end{array}$ & $\begin{array}{c}\text { Grade } 4 \\
n(\%)\end{array}$ \\
\hline \multicolumn{5}{|l|}{ Haematology } \\
\hline Neutrophils & $30(21)$ & $34(23)$ & $10(7)$ & $2(1)$ \\
\hline Haemoglobin & $84(58)$ & $30(21)$ & $4(3)$ & 0 \\
\hline Platelets & $18(12)$ & $4(3)$ & $4(3)$ & 0 \\
\hline \multicolumn{5}{|l|}{ Chemistry } \\
\hline Hypoalbuminemia & $38(26)$ & $37(25)$ & $10(7)$ & 0 \\
\hline Alk phos & $44(30)$ & $4(3)$ & $3(2)$ & 0 \\
\hline AST (SGOT) & $79(54)$ & $19(13)$ & $4(3)$ & 0 \\
\hline ALT (SGPT) & $59(40)$ & $42(29)$ & $18(12)$ & 0 \\
\hline Bilirubin & $8(5)$ & $4(3)$ & 0 & 0 \\
\hline Creatinine & $21(14)$ & 0 & 0 & I (I) \\
\hline Creatine Kinase & $13(9)$ & $7(5)$ & $4(3)$ & $1(1)$ \\
\hline Hyperglycaemia & $84(58)$ & $31(2 I)$ & $7(5)$ & $2(1)$ \\
\hline Hypoglycaemia & $5(3)$ & I (I) & $2(1)$ & 0 \\
\hline Hyperkalemia & $8(5)$ & $2(1)$ & $2(1)$ & 0 \\
\hline Hypokalemia & $43(29)$ & 0 & $6(4)$ & 0 \\
\hline Hypernatremia & $13(9)$ & 0 & 0 & 0 \\
\hline Hyponatremia & $46(32)$ & 0 & II (8) & I (I) \\
\hline
\end{tabular}

a Worst grade between the first trabectedin dose and 30 days after the last trabectedin dose. ${ }^{b}$ For each lab test, $n=146 / 147$ treated patients for whom postbaseline lab data are available except for creatine kinase, hyperglycaemia, and hypoglycaemia in which cases $n=145 / 147$.

TEAEs were reported as grade 4 pelvic haemorrhage for one subject, and cardiac arrest for one subject, both occurring at Cycle 2.

\section{DISCUSSION}

Trabectedin, a novel marine-derived compound with a unique mechanism of action, has shown activity against a variety of 
Table 5 Treatment-emergent drug-related grade I -4 adverse events in $\geqslant 2 \%$ of patients

\begin{tabular}{|c|c|c|c|c|c|}
\hline & \multirow[b]{2}{*}{ Total } & \multicolumn{4}{|c|}{ All treated patients $(N=147)$} \\
\hline & & \multicolumn{4}{|c|}{ Toxicity grade ${ }^{a}$} \\
\hline WHO preferred term & $n(\%)$ & | (\%) & $2(\%)$ & $3(\%)$ & $4(\%)$ \\
\hline SGPT (ALT) increased & $41(28)$ & $6(4)$ & $20(14)$ & $14(10)$ & ( (I) \\
\hline Granulocytopaenia & $35(24)$ & $9(6)$ & $17(22)$ & $7(5)$ & $2(1)$ \\
\hline Nausea & $102(69)$ & $63(43)$ & $31(21)$ & $8(5)$ & 0 \\
\hline Vomiting & $69(47)$ & $38(26)$ & $23(16)$ & $8(5)$ & 0 \\
\hline Fatigue & $88(60)$ & $36(24)$ & $44(30)$ & $8(5)$ & 0 \\
\hline Gamma-GT increased & $9(6)$ & $3(2)$ & $3(2)$ & $3(2)$ & 0 \\
\hline SGOT (AST) increased & $21(14)$ & $8(5)$ & $10(7)$ & $2(1)$ & I (I) \\
\hline Abdominal pain & $16(11)$ & $7(5)$ & $6(4)$ & $3(2)$ & 0 \\
\hline Constipation & $48(33)$ & $23(16)$ & $22(15)$ & $3(2)$ & 0 \\
\hline Creatine phosphokinase increased & $7(5)$ & $2(1)$ & $2(1)$ & $2(1)$ & $\mid(1)$ \\
\hline Hypokalemia & $4(3)$ & I ( I) & 0 & $3(2)$ & 0 \\
\hline Thrombocytopaenia & $7(5)$ & $2(1)$ & $2(1)$ & $2(1)$ & I (I) \\
\hline Somnolence & $17(12)$ & $8(5)$ & $6(4)$ & $3(2)$ & 0 \\
\hline
\end{tabular}

aToxicity grade: $\mathrm{NCl}$ common terminology criteria, version 2.0. Incidence is based on the number of patients.

preclinical solid tumour models. In a similar Phase II trial of trabectedin administered every 3 weeks in advanced ovarian cancer Sessa et al (2005) showed promising results with limited toxicities. Confirmation of these early results has been seen in the recently completed every 3 week regimen two arm randomised ET743:B-026 study (Del Campo et al, 2006; McMeekin et al, 2007). The results of the present study and those reported by Sessa et al (2005), Del Campo et al (2006), and McMeekin et al (2007) demonstrate the effectiveness of trabectedin as a single agent in the platinum-sensitive patient population with respect to ORR and disease stabilisation. The most common TEAE in the three studies was a self-limiting reversible elevation in liver enzymes, with noncumulative myelosuppression being a secondary common adverse event.

The efficacy results seen in all platinum-sensitive patients treated every 3 weeks with trabectedin in the SENDO study (Sessa et al, 2005) showed a response rate of $43.5 \%$ (95\% CI: $23-65 \%$ ) with TTP of 7.9 months (95\% CI: 7.5-14.1 months). Similarly, the ET-743:B-026 study (Del Campo et al, 2006) showed a response rate of $37.4 \%$ (95\% CI: $28.2-47.3 \%$ ) with TTP of 6.8 months (95\% CI: 5.5-7.4 months). These results trend favourably $v s$ the response rate of $29 \%$ ( $95 \%$ CI: $18.2-41.9 \%$ ) and TTP of 5.2 months (95\% CI: 3.1-6.5 months) seen in this weekly trabectedin-treated schedule. However, differences in patient numbers as well as number of prior treatment regimens could contribute to the efficacy variations between the three studies.

In the case of platinum-resistant/refractory disease, response rates were low in this weekly schedule study (6.3\% (95\% CI: 2.1 $14.2 \%)$, and less than that seen with the every 3 week trabectedin schedule (Sessa et al, 2005; Del Campo et al, 2006; McMeekin et al, 2007) where responses seen were $7 \%$ in all patients, and $14.3 \%$ (95\% CI: $4.0-32.7 \%)$ in patients with one prior platinum-based regimen. The reduction in response observed in this study compared to the every 3 week data could be related to the inclusion of a higher percentage of third line and refractory patients in our study. The small but consistent number of durable responses seen in all three phase II trabectedin studies suggests that trabectedin could be combined with another active agent in this difficult to treat chemo-resistant patient population.

In contrast to the response rates, a more interesting finding in our study was the duration of response 5.2 months in platinumsensitive and 4.2 months in platinum-resistant/refractory patient cohorts. The progression-free rate at 6 months was 44 and $11 \%$ for the platinum-sensitive and -resistant/refractory groups, respectively.

Trabectedin toxicity was manageable in this study, with only $7 \%$ of the patients discontinuing therapy due to a drug-related TEAE. Study related, regardless of association with drug, nausea (79\%) and vomiting $(56 \%)$ were common, although these were generally not severe (mostly grade 1 or 2 ) and did not limit therapy. Study related, regardless of association with drug, fatigue was reported in $70 \%$ of patients; however, the incidence of grade $3(7 \%)$ or $4(0 \%)$ fatigue was minimal. Grade 3 and 4 granulocytopaenia occurred much less frequently in the current trial (6\%) compared with the Sessa trial (41\%) (Sessa et al, 2005). The most common drugrelated TEAE was dose- and schedule-dependent, self-limiting transaminitis (elevated, ALT $20 \%$ ), which generally peaked by day 4 or 5 and returned to baseline by day 14 .

In summary, trabectedin given as a single agent once weekly for 3 of 4 weeks is effective for the treatment of advanced relapsed ovarian cancer in the platinum-sensitive patient population. Responses in the heavily pretreated resistant/refractory patient population were low in both schedules (every week vs every 3 weeks). Myelosuppression appeared to be less in weekly schedule ( $6 \%$ vs 18\%), whereas dose reductions and dose delays due to acute transaminitis was $42 \%$ in the weekly regimen, which is greater than the $34 \%$ reported in the every 3 week regimen (Sessa et al, 2005). Further studies in combination with effective and potentially synergistic agents in this patient population are ongoing. The chronicity of recurrent ovarian cancer suggests the development of more non-cross-resistant drug regimens for on-going palliative treatment. The reported results on tolerability, clinical efficacy, and durability demonstrate the potential usefulness of trabectedin as a novel single agent in advanced platinum-sensitive ovarian cancer in providing an alternative to existing single agents or combination treatments for ovarian cancer.

\section{ACKNOWLEDGEMENTS}

Special thanks to Ovidiu C Trifan, MD PhD, Bart Michiels, $\mathrm{PhD}$, Youn C Park, PhD, Denise Williams MD, Xiaolong Luo, PhD, David J Wagner, PharmD, Larry J Rosenberg, $\mathrm{PhD}$, and Jennifer Smit for their valuable contributions to the study and development of the paper. We also thank Namit Ghildyal, PhD for his writing contributions. This study was supported by Johnson \& Johnson Pharmaceutical Research \& Development, LLC.

\section{Authors' disclosures of potential conflicts of interest}

The following authors or their immediate family members have indicated a financial interest. Acted as a consultant within the last 2 years: C Krasner, Johnson \& Johnson Pharmaceutical Research \& Development, LLC; S Campos, Johnson \& Johnson Pharmaceutical Research \& Development, LLC. Received more than $\$ 2000$ a year from a company for either of the last 2 years: C Krasner, Johnson \& Johnson Pharmaceutical Research \& Development, LLC, S Campos, Johnson \& Johnson Pharmaceutical Research \& Development, LLC.

\section{REFERENCES}

American Cancer Society (2005) Cancer Facts and Figures. Atlanta, Ga American Society of Clinical Oncology. Use of hematopoietic colonystimulating factors: evidence-based, practice guidelines
Del Campo J, Roszak A, Ciuleanu T, Bidzinski M, Hogberg T, Wojtukienicz M, Boman K, Poveda A, Westermann A, Izquierdo M (2006) Phase II open label randomized study of trabectedin $(\mathrm{T})$ given as two different 
dosing schedules in women with platinum-sensitive, recurrent ovarian carcinoma: preliminary results. ASCO Ann Meet Proc 24: 5031

Erba E, Bergamaschi D, Bassano L, Damia G, Ronzoni S, Faircloth GT, D'Incalci M (2001) Ecteinascidin-743 (ET-743), a natural marine compound, with a unique mechanism of action. Eur J Cancer 37: 97-105

Garcia AA, O'Meara A, Bahador A, Facio G, Jeffers S, Kim DY, Roman L (2004) Phase II study of gemcitabine and weekly paclitaxel in recurrent platinum-resistant ovarian cancer. Gynecol Oncol 93: 493-498

Gordon AN, Fleagle JT, Guthrie D, Parkin DE, Gore ME, Lacave AJ (2001) Recurrent epithelial ovarian carcinoma: a randomized phase III study of pegylated liposomal doxorubicin versus topotecan. J Clin Oncol 19: $3312-3322$

Harper P (2002) Current clinical practices for ovarian cancers. Semin Oncol 29: $3-6$

Hendriks HR, Fiebig HH, Giavazzi R, Langdon SP, Jimeno JM, Faircloth GT (1999) High antitumour activity of ET743 against human tumour xenografts from melanoma, non-small-cell lung and ovarian cancer. Ann Oncol 10: $1233-1240$

Izbicka E, Lawrence R, Raymond E, Eckhardt G, Faircloth G, Jimeno J, Clark G, Von Hoff DD (1998) In vitro antitumor activity of the novel marine agent, ecteinascidin-743 (ET-743, NSC-648766) against human tumors explanted from patients. Ann Oncol 9: 981-987

Jimeno J, Faircloth G, Cameron L (1996) Progress in the acquisition of new marine-derived anticancer compounds: development of ecteinascidin743 (ET-743). Drugs Fut 21: 1155-1165

Li WW, Takahashi N, Jhanwar S, Cordon-Cardo C, Elisseyeff Y, Jimeno J, Faircloth G, Bertino JR (2001) Sensitivity of soft tissue sarcoma cell lines to chemotherapeutic agents: identification of ecteinascidin-743 as a potent cytotoxic agent. Clin Cancer Res 7: 2908-2911

Mandola MV, Kolb EA, Scotto KW (2005) Poly (ADP-ribose) polymerase (PARP) contributes to cellular sensitivity to trabectedin (Yondelis ${ }^{\mathrm{TM}}$ ). Proc Am Assoc Cancer Res 46: 972 (abstract 4122)

Markman M, Bookman MA (2000) Second-line treatment of ovarian cancer. Oncologist 5: 26-35

Markman M, Kennedy A, Webster K (2001) Phase 2 trial of single-agent gemcitabine (GEM) in platinum (PLAT)/paclitaxel (PAC) refractory ovarian cancer (ROC). Proc Am Soc Clin Oncol 20: 2001 (abstract 813)

Martinez EJ, Corey EJ, Owa T (2001) Antitumor activity- and gene expression-based profiling of ecteinascidin Et 743 and phthalascidin $\mathrm{Pt}$ 650. Chem Biol 8: $1151-1160$

McMeekin DS, del Campo JM, Colombo N, Krasner C, Roszak A, Braly P, Ciuleanu TE, Lebedinsky C, Izquierdo MA, Sessa C (2007) Trabectedin (T) in relapsed advanced ovarian cancer (ROC): a pooled analysis of three phase II studies. ASCO Ann Meet Proc Part I 25: 5579

McMeekin DS, Krasner C, Chan S, Braly P, Kaye S, Provencher D, Trifan OC, Michiels B, Gore M (2005) Final results of a phase II study of weekly trabectedin in second/third line ovarian carcinoma. ASCO Ann Meet Proc 23: 5011

McMeekin DS, Manikas G, Crispens M, Orza AM, Braly P, Doering D, Trifan OC, Michiels B, Markman M (2004) A phase II study of trabectedin (ET-743) as a second line therapy in patients with persistent or recurrent endometrial carcinoma. ASCO Ann Meet Proc 22: 5086

Minuzzo M, Marchini S, Broggini M, Faircloth G, D’Incalci M, Mantovani R (2000) Interference of transcriptional activation by the antineoplastic drug ecteinascidin-743. Proc Natl Acad Sci USA 97: 6780-6784

National Cancer Institute Common Toxicity Criteria V2.0 (2006). NH Publication: Handydex, LLC

National Comprehensive Cancer Network (2005) Clinical Practice Guidelines in Oncology, Version 1. (C)2006 National Comprehensive Cancer Network, Inc: Jenkintown, PA, Available at http://www.neen.org

Papadimitriou CA, Fountzilas G, Aravantinos G, Kalofonos C, Moulopoulos LA, Briassoulis E, Gika D, Dimopoulos MA (2004) Second-line chemotherapy with gemcitabine and carboplatin in paclitaxel-pretreated, platinum-sensitive ovarian cancer patients. A Hellenic Cooperative Oncology Group Study. Gynecol Oncol 92: 152-159

Pommier Y, Kohlhagen G, Bailly C, Waring M, Mazumder A, Kohn KW (1996) DNA sequence- and structure-selective alkylation of guanine N2 in the DNA minor groove by ecteinascidin 743 , a potent antitumor compound from the Caribbean tunicate Ecteinascidia turbinata. Biochemistry 35: 13303-13309
Puchalski TA, Ryan DP, Garcia-Carbonero R, Demetri GD, Butkiewicz L, Harmon D, Seiden MV, Maki RG, Lopez-Lazaro L, Jimeno J, Guzman C, Supko JG (2002) Pharmacokinetics of ecteinascidin 743 administered as a $24-\mathrm{h}$ continuous intravenous infusion to adult patients with soft tissue sarcomas: associations with clinical characteristics, pathophysiological variables and toxicity. Cancer Chemother Pharmacol 50: 309-319

Rose PG (2005) Pegylated liposomal doxorubicin: optimizing the dosing schedule in ovarian cancer. Oncologist 10: 205-214

Ryan DP, Supko JG, Eder JP, Seiden MV, Demetri G, Lynch TJ, Fischman AJ, Davis J, Jimeno J, Clark JW (2001) Phase I and pharmacokinetic study of ecteinascidin 743 administered as a 72-hour continuous intravenous infusion in patients with solid malignancies. Clin Cancer Res 7: $231-242$

Salazar R, Pardo B, Majem M, García M, Montes A, Cuadra C, Ciruelos E, Cortés-Funes H, Lebedinsky C, Paz-Ares L (2006) Phase I clinical and pharmacological trial of trabectedin $(\mathrm{T})$ in $3 \mathrm{~h}$ infusion every 3 weeks $(3 \mathrm{~h} / \mathrm{q} 3 \mathrm{w})$ in patients with advanced cancer and hepatic function disorder. J Clin Oncol 2006 ASCO Annual Meeting Proceedings 24: 2080

Sarah D, Verschoyle RD, Greaves P (2003) Complete protection by highdose dexamethasone against the hepatotoxicity of the novel antitumor drug yondelis (ET-743) in the rat. Cancer Res 63: 5902-5908

Sessa C, De Braud F, Perotti A, Bauer J, Curigliano G, Noberasco C, Zanaboni F, Gianni L, Marsoni S, Jimeno J, D'Incalci M, Dall'o E, Colombo N (2005) Trabectedin for women with ovarian carcinoma after treatment with platinum and taxanes fails. J Clin Oncol 23: 1867-1874

Taamma A, Misset JL, Riofrio M, Guzman C, Brain E, Lopez Lazaro L, Rosing H, Jimeno JM, Cvitkovic E (2001) Phase I and pharmacokinetic study of ecteinascidin-743, a new marine compound, administered as a 24-h continuous infusion in patients with solid tumors. J Clin Oncol 19: $1256-1265$

Takebayashi Y, Pourquier P, Zimonjic DB, Nakayama K, Emmert S, Ueda T, Urasaki Y, Kanzaki A, Akiyama SI, Popescu N, Kraemer KH, Pommier Y (2001) Antiproliferative activity of ecteinascidin 743 is dependent upon transcription-coupled nucleotide-excision repair. Nat Med 7: 961-966

Technology Appraisal Guidance (2005) Paclitaxel, pegylated liposomal doxorubicin hydrochloride and topotecan for second-line or subsequent treatment of advanced ovarian cancer, Excellence NIfC (ed) Vol. No. 91. London, UK: National Institute for Clinical Excellence, London, UK

Therasse P, Arbuck SG, Eisenhauer EA, Wanders J, Kaplan RS, Rubinstein L, Verweij J, Van Glabbeke M, van Oosterom AT, Christian MC, Gwyther SG (2000) New guidelines to evaluate the response to treatment in solid tumors. European Organization for Research and Treatment of Cancer, National Cancer Institute of the United States, National Cancer Institute of Canada. J Natl Cancer Inst 92: 205-216

Twelves C, Hoekman K, Bowman A, Vermorken JB, Anthoney A, Smyth J, van Kesteren C, Beijnen JH, Uiters J, Wanders J, Gomez J, Guzman C, Jimeno J, Hanauske A (2003) Phase I and pharmacokinetic study of Yondelis (Ecteinascidin-743; ET-743) administered as an infusion over $1 \mathrm{~h}$ or $3 \mathrm{~h}$ every 21 days in patients with solid tumours. Eur J Cancer 39: $1842-1851$

Valoti G, Nicoletti MI, Pellegrino A, Jimeno J, Hendriks H, D’Incalci M, Faircloth G, Giavazzi R (1998) Ecteinascidin-743, a new marine natural product with potent antitumor activity on human ovarian carcinoma xenografts. Clin Cancer Res 4: 1977-1983

van Kesteren C, de Vooght MM, Lopez-Lazaro L, Mathot RA, Schellens JH, Jimeno JM, Beijnen JH (2003) Yondelis (trabectedin, ET-743): the development of an anticancer agent of marine origin. Anticancer Drugs 14: $487-502$

Villalona-Calero MA, Eckhardt SG, Weiss G, Hidalgo M, Beijnen JH, van Kesteren C, Rosing H, Campbell E, Kraynak M, Lopez-Lazaro L, Guzman C, Von Hoff DD, Jimeno J, Rowinsky EK (2002) A phase I and pharmacokinetic study of ecteinascidin-743 on a daily x 5 schedule in patients with solid malignancies. Clin Cancer Res 8: 75-85

Yovine A, Riofrio M, Blay JY, Brain E, Alexandre J, Kahatt C, Taamma A, Jimeno J, Martin C, Salhi Y, Cvitkovic E, Misset JL (2004) Phase II study of ecteinascidin-743 in advanced pretreated soft tissue sarcoma patients. J Clin Oncol 22: $890-899$

Zewail-Foote M, Hurley LH (1999) Ecteinascidin 743: a minor groove alkylator that bends DNA toward the major groove. J Med Chem 42: $2493-2497$ 